\title{
Energy Consumption of Taekwondo Practitioners due to a Thigh Muscle Extracted by CT Scan
}

\author{
Changmo $\mathrm{Kim}^{*}$, Insuk $\mathrm{Ha}^{* *}$, SangBock Lee ${ }^{* * *}$ \\ Dept. of Medical Bioengineering, Chungbuk National University *, Doctor Taekwondo Training Center**, Dept. of Radiology, \\ Nambu University ${ }^{* * *}$

\section{CT Scan으로 추출한 허벅지 근육량에 따른 태권도 수련자의 에너지 소모량}

\author{
김창모*, 하인숙**, 이상복*** \\ 충북대학교 의용생체공학과 ${ }^{*}$, 박사태권도장**, 남부대학교 방사선학과 ${ }^{* *}$
}

\begin{abstract}
Despite the suzerain of Korea Taekwondo physical activity and a corresponding lack of basic research on energy consumption and the status of this research is urgent. In this study, the sensor (SenseWear ${ }^{\circledR}$ PRO2 Armband), using physical activity were obtained in Taekwondo, and body composition data were obtained by Inbody 520, We were thigh scan using CT scanner and thigh muscle area by CT scan data were acquired.

Result of analysis, average thigh muscle area of experimenter 8 people was $132.79 \mathrm{~cm}^{2}$, Of $20 \mathrm{~cm}$ above the patella thigh was a $178.79 \mathrm{~cm}^{2}$. Thigh circumference and muscle area showed that the correlation.

The average energy consumption per minute was 6.94 calories, and thigh muscle area and average energy consumption per minute also showed that correlation.
\end{abstract}

Key word : Taekwondo Practitioners, Thigh Muscle Area, CT Image, Energy Consumption

\section{요약}

우리나라는 태권도의 종주국임에도 불구하고 신체활동량과 그에 따른 에너지 소모량에 대한 기초연구가 미흡하며 이에 대한 연구가 시급한 상태이다. 본 연구에서는 센서(SenseWear ${ }^{\circledR} \mathrm{PRO}_{2}$ Armband)를 이용하여 태권도의 신체활동 량을 획득하였고, Inbody 520을 통하여 체성분 데이터를 획득 하였으며, CT로 하체부위(허벅지)를 스캔하여 허벅지 근육면적 데이터를 추출하였다. 획득된 데이터를 이용하여 허벅지 둘레와 근육면적의 상관관계, 허벅지 근육면적과 분 당 에너지 소모량의 상관관계를 분석하였다. 분석결과 실험자 8 명의 평균 허벅지 근육면적은 $132.79 \mathrm{~cm} 2$ 였으며, 무 릎뼈(Pattela) 위 $20 \mathrm{~cm}$ 의 평균 허벅지 전체 면적은 $178.79 \mathrm{~cm} 2$ 이었다. 실험자들의 허벅지 둘레와 근육면적은 상관 관계가 있는 것으로 나타났다. 실험자들의 평균 분당 에너지 소모량은 6.94 칼로리였으며, 허벅지 근육면적과 평균 분 당 에너지 소모량도 상관관계가 있는 것으로 나타났다. 


\section{I. 서론}

건강학자들은 현대인이 수명의 연장으로 인하여 정년 퇴직 이후나 일손을 놓는 상태에서 인생의 $1 / 4 \sim 1 / 5$ 를 살아가야 하는데 노년까지 안락한 삶을 누 리기 위해서는 국가적 차원의 문제뿐만 아니라 건강 을 위한 체력 즉 근력, 근지구력, 유연성, 심근혈류 능 력 향상, 신체의 구성 등이 청소년기부터 교육이 필요 하다.

건강을 잃는 문제는 복지국가 실현을 목표로 하는 국가나 사회의 책임으로 남게 된다. 성인병의 치료 경 비는 개인과 국가재정에 막대한 손실을 가져오게 된 다. 국민 건강을 위한 해결방안은 청소년기부터 운동 습관을 갖도록 프로그램을 개발하고 건강교육을 하여 운동의 생활화로 건강 체력을 갖게 함으로서 복지국 가를 실현하는 것이다.

태권도는 세계적인 스포츠로서 200여개국가에서 약 1 억여 만 명이 넘는 인구가 태권도를 수련하고 있다 ${ }^{[1]}$. 태권도 수련은 전신을 전후, 상하, 좌우로 균등하고 합 리적으로 움직여서 평상시 많이 사용하지 않는 근육 을 충분히 활용하기 때문에 손과 발의 발달이 어느 한 쪽으로만 치우칠 우려가 없는 이상적인 신체활동이다 ${ }^{[2]}$. 스포츠로서 태권도를 수련하는 것은 건강의 유지 및 증진, 체력단련과 호신능력의 배양에도 매우 긍정 적인 인격 형성을 가능하게 한다 ${ }^{[3]}$. 그리고 태권도는 당기는 근육의 힘보다는 차고 지르는 동작들이 많고 수련 과정에서도 뻗어주는 스트레칭 효과를 줌으로서 신체 발달의 많은 도움이 된다 ${ }^{[4]}$. 대부분의 태권도 수 련자들은 경기보다는 자신의 신체 단련과 건강을 위 해 태권도 수련을 하고 있음을 알 수 있으며, 수련자 들은 고난도의 기술보다 기본동작과 품새, 겨루기, 호 신술 등에 중점을 두고 수련하고 있는 것으로 알려지 고 있다 ${ }^{[5]}$. 우리나라는 태권도의 종주국임에도 불구하 고 태권도 수련과정에서 얻어지는 기본동작과 품새의 체계적이며 과학적인 구조화가 미흡할 뿐만 아니라, 품새 수련과 관련하여 선행연구가 이루어졌지만, 신체 활동량과 그에 따른 에너지 소모량에 대한 기초연구 가 미흡하며 이에 대한 연구가 시급한 상태이다.

본 연구에서는 센서(SenseWear ${ }^{\circledR} \mathrm{PRO}_{2}$ Armband)를
이용하여 태권도의 신체활동량, Inbody 520 을 통하여 체성분 데이터, CT로 하체부위(허벅지)를 스캔하여 허 벅지 근육면적 데이터를 추출할 것이다. 획득된 데이 터를 이용하여 허벅지 둘레와 근육면적의 상관관계, 허벅지 근육면적과 분당 에너지 소모량의 상관관계를 분석하고자 한다.

\section{II. 재료 및 방법}

본 연구를 위하여 체성분 추출은 바이오스이스사의 $\operatorname{InBody} 520^{\circledR}$ 을 이용하여 전체근육량을 측정하였다.

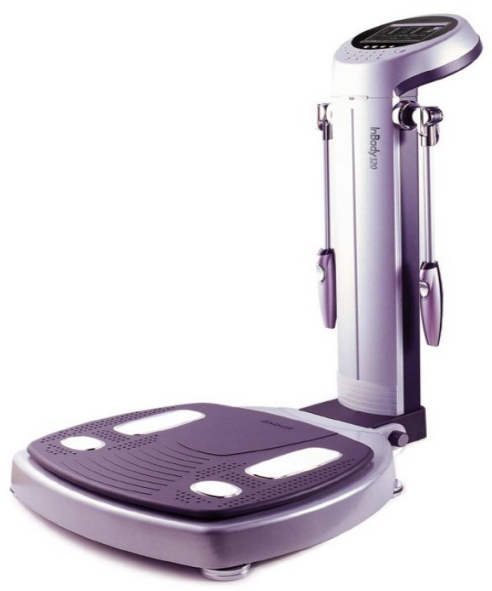

Fig. 1. Body Composition Analyzer (Inbody520) Biospace

신체 활동량 데이터 획득은 BodyMedia사의 SenseWear ${ }^{\circledR} \mathrm{PRO}_{2}$ Armband(이하 Armband)에 내장되어 있는 2차원 가속도센서(Fig. 2)를 Fig. 3과 같이 태극 품 새 시범자의 오른쪽 상완에 착용하여 획득하였다.

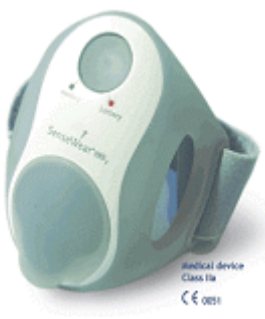

Fig. 2. SenseWear ${ }^{\circledR}$ $\mathrm{PRO}_{2}$ Armband

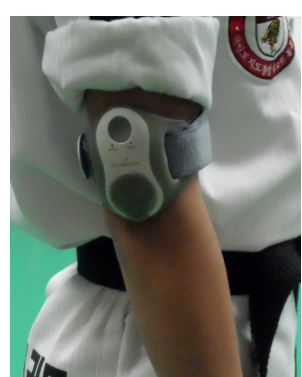

Fig. 3. Wearing the armband 
이 장비는 $\mathrm{MEMS}$ (micro electro mechanical system) 기술을 적용하여 개발된 장비이다 ${ }^{[6]}$. Armband를 실험 대상자에 착용하여 데이터를 획득한 후 획득된 데이 터를 InnerView(TM) Research Software ${ }^{[5]}$ 를 이용하여 분 석하였다.

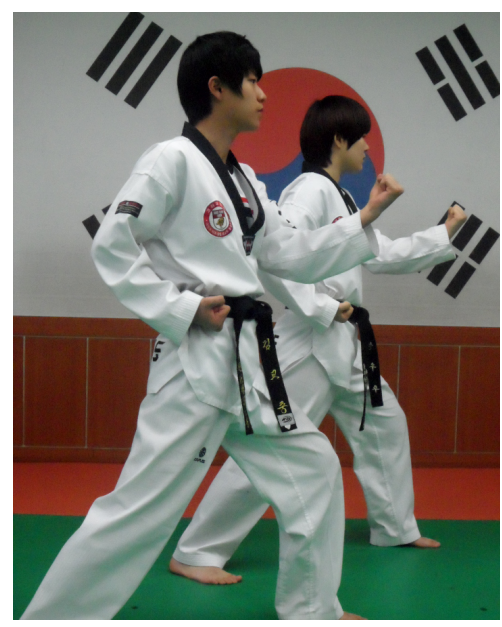

Fig. 4. Obtained of Taekwondo physical activity

허벅지 근육면적 데이터 획득을 위하여 실험 대상 자들의 동의에 의하여 슬개골(Patella) 끝단 $20 \mathrm{Cm}$ 부위 를 기준으로 Fig 5에 보이는 GE사 16 Channel CT Scanner를 이용하여 이미지를 얻은 후 CT Scanner System에서 제공되는 Software를 이용하여 영상처리를 하였다 ${ }^{[7]}$.

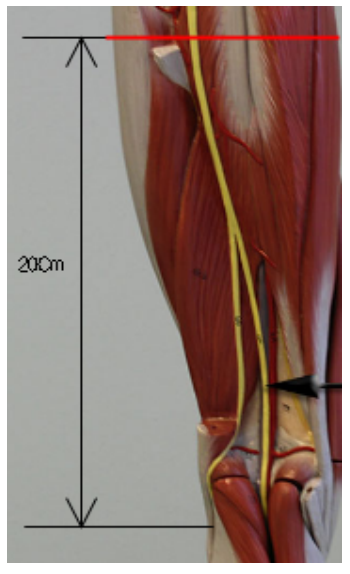

(a)

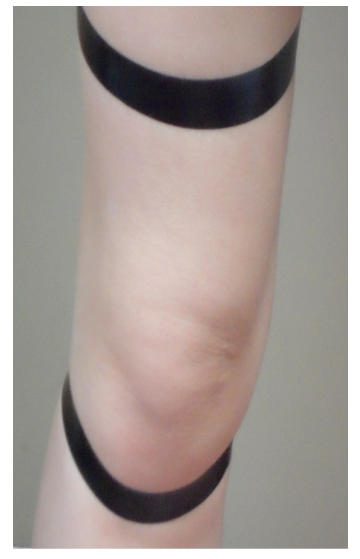

(b)

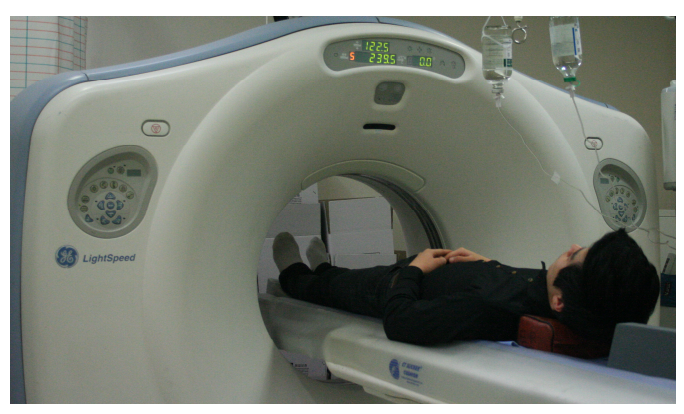

(c)

Fig. 5. Acquisition process of muscle

(a) Picture of the thigh muscles, (b) CT scan location,

(c) GE Light Speed Scanner

영상처리는 획득하고자 하는 부위의 허벅지 영상에 서 근육에 해당하는 CT Number 만을 표시하는 처리 로써 Window와 Level을 조절하여 수행하였다.

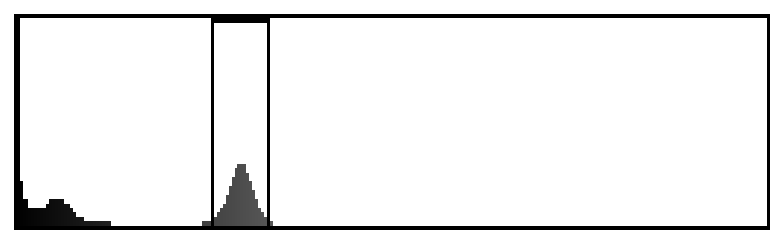

Fig. 6. Windows and Level

근육면적 계산을 위하여 Image ${ }^{\circledR}$ 프로그램을 이용 하여 근육부분의 영상만 표시하였다 ${ }^{[8]}$.

Image $)^{\circledR}$ 는 $\mathrm{NIH}$ (National Institutes of Health)에서 개 발한 공개 프로그램[8]이다.

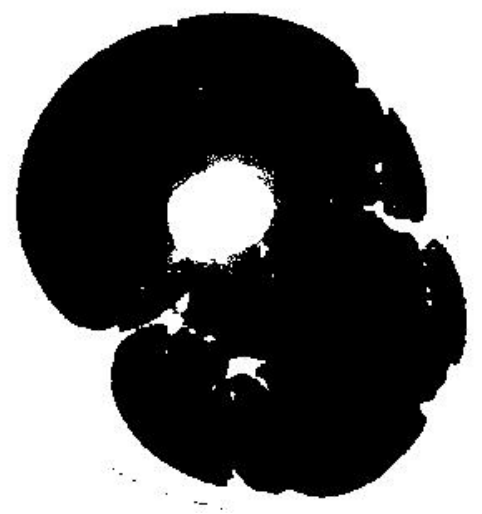

Fig. 7. Image of extracted thigh muscle 
본 연구를 위한 실험자들은 태권도 유단자(2 4단) 8명(평균연령 20.6세, 평균신장 $171.11 \mathrm{Cm}$, 평균 몸무게 $6.1 \mathrm{Kg}$ ) 을 대상으로 태극 1장에서 8장까지 품새 수행 구령 없이 빠르게 수행토록 하여 신체 활동량을 측정 하였다.

Table 1. Experimenter status

\begin{tabular}{c|c|c|c|c}
\hline ID & Age & Height & Weight & Sex \\
\hline T1 & 24 & 162 & 50 & $\mathrm{~F}$ \\
\hline T2 & 18 & 164 & 51.3 & $\mathrm{M}$ \\
\hline T3 & 20 & 181 & 68.4 & $\mathrm{M}$ \\
\hline T4 & 20 & 177 & 61.4 & $\mathrm{M}$ \\
\hline T5 & 23 & 160 & 56.9 & $\mathrm{~F}$ \\
\hline T6 & 17 & 165 & 60.9 & $\mathrm{~F}$ \\
\hline T7 & 23 & 175 & 58.3 & $\mathrm{M}$ \\
\hline T8 & 20 & 177 & 66.7 & $\mathrm{M}$ \\
\hline
\end{tabular}

III. 결과

실험 대상자들의 체성분 분석결과는 Table 2 와 같이 나타났다. 체성분 중 전체 근육량은 평균값은 $48.16 \mathrm{Kg}$ 로 나타났다.

Table 2. Data acquired by the Inbody

\begin{tabular}{c|c}
\hline ID & 전체근육량 [단위 $: \mathrm{Kg}]$ \\
\hline T1 & 38 \\
\hline T2 & 41.7 \\
\hline T3 & 59.5 \\
\hline T4 & 51 \\
\hline T5 & 40.2 \\
\hline T6 & 40.9 \\
\hline T7 & 51 \\
\hline T8 & 54.5 \\
\hline T9 & 56.7
\end{tabular}

실험자들의 태극 품새 1장부터 8장까지 연속된 동작 에서 획득된 신체 활동량은 Table 3과 같이 나타났다.
Table 3에서 활동시간은 3분에서 7 분 사이로 나타났고, 분당 에너지 소모량은 5.56 에서 $9.00 \mathrm{Cal}$ 로 나타났다.

Table 3. Data obtained by Armband

\begin{tabular}{c|c|c|c|c}
\hline I0 & $\begin{array}{c}\text { 총 에너지 } \\
\text { 소모량 }\end{array}$ & $\begin{array}{c}\text { 활동시간 } \\
\text { (min) }\end{array}$ & $\begin{array}{c}\text { 에너지 } \\
\text { 소모량 }\end{array}$ & $\begin{array}{c}\text { 분당 에너지 } \\
\text { 소모량 }\end{array}$ \\
\hline $\mathrm{T} 1$ & 49 & 6 & 33.33 & 5.56 \\
\hline $\mathrm{T} 2$ & 51.67 & 6.33 & 40.33 & 6.37 \\
\hline $\mathrm{T} 3$ & 61 & 6 & 54 & 9.00 \\
\hline $\mathrm{T} 4$ & 40.5 & 3 & 22.5 & 7.50 \\
\hline $\mathrm{T} 5$ & 35.5 & 5 & 28.5 & 5.70 \\
\hline $\mathrm{T} 6$ & 59 & 7 & 45 & 6.43 \\
\hline $\mathrm{T} 7$ & 56.5 & 6.5 & 48.5 & 7.46 \\
\hline $\mathrm{T} 8$ & 37 & 4 & 30 & 7.50 \\
\hline
\end{tabular}

허벅지 둘레에 따른 허벅지 근육면적은 Table 4.에 나타내었다. 허벅지 근육면적은 $104.204 \mathrm{~cm}^{2}$ 부터 $165.099 \mathrm{~cm}^{2}$ 였으며 허벅지 전체 면적은 $159.618 \mathrm{~cm}^{2}$ 부터 $202.276 \mathrm{~cm}^{2}$ 이었다.

Table 4. The total area of thigh and thigh muscle area

[Above of $20 \mathrm{~cm}$ from knee joint point]

\begin{tabular}{c|c|c|c}
\hline ID & $\begin{array}{c}\text { 전체면적 } \\
\text { [단위 }: \mathrm{cm}^{2} \text { ] }\end{array}$ & $\begin{array}{c}\text { bone면적 } \\
\text { [단위 }: \mathrm{cm}^{2} \text { ] }\end{array}$ & $\begin{array}{c}\text { 근육면적 } \\
\text { [단위 }: \mathrm{cm}^{2} \text { ] }\end{array}$ \\
\hline $\mathrm{T} 1$ & 160.213 & 5.551 & 104.204 \\
\hline $\mathrm{T} 2$ & 159.618 & 5.085 & 126.866 \\
\hline $\mathrm{T} 3$ & 185.027 & 7.194 & 159.970 \\
\hline $\mathrm{T} 4$ & 167.417 & 6.731 & 134.190 \\
\hline $\mathrm{T} 5$ & 165.450 & 5.911 & 141.604 \\
\hline $\mathrm{T} 6$ & 196.253 & 7.601 & 165.099 \\
\hline $\mathrm{T} 7$ & 202.276 & 5.492 & 120.157 \\
\hline $\mathrm{T} 8$ & 194.047 & 3.929 & 110.192 \\
\hline
\end{tabular}

허벅지 근육 면적에 따른 분당 에너지 소모량은 Table 5.에 나타내었다. 분당 에너지 소모량은 5.56에서 $9.00 \mathrm{Cal}$ 로 나타났다. 
Table 5. Thigh muscle area and energy consumption per minute

\begin{tabular}{c|c|c}
\hline ID & $\begin{array}{c}\text { 분당에너지 소모량 } \\
\text { [단위:cal] }\end{array}$ & $\begin{array}{c}\text { 허벅지 근육 면적 } \\
\text { [단위 : } \mathrm{cm}^{2} \text { ] }\end{array}$ \\
\hline $\mathrm{T} 1$ & 5.56 & 104.204 \\
\hline $\mathrm{T} 2$ & 6.37 & 126.866 \\
\hline $\mathrm{T} 3$ & 9.00 & 159.970 \\
\hline $\mathrm{T} 4$ & 7.50 & 134.190 \\
\hline $\mathrm{T} 5$ & 5.70 & 141.604 \\
\hline $\mathrm{T} 6$ & 6.43 & 165.099 \\
\hline $\mathrm{T} 7$ & 7.46 & 120.157 \\
\hline $\mathrm{T} 8$ & 7.50 & 110.192 \\
\hline
\end{tabular}

\section{$\mathrm{IV}$. 토론 및 고찰}

체성분 분석에서 획득한 평균 근육량 $48.16 \mathrm{Kg}$ 과 분 당 평균 에너지 소모량은 7.09 Calories 가 필요한 것으 로 나타났다. 실험 대상자들의 전체 근육량과 분당 에 너지 소모량을 비교해 보면 Fig. 8 에 보이는 것처럼 근육량이 많으면 분당 에너지 소모량이 증가하는 것 으로 나타났으나 완전 비례로 증가하는 것으로 나타 나지는 않았다. 이러한 이유는 신체 활동에서 사용하 는 근육의 일시적 에너지 소모가 영향을 미치는 것으 로 사료된다.

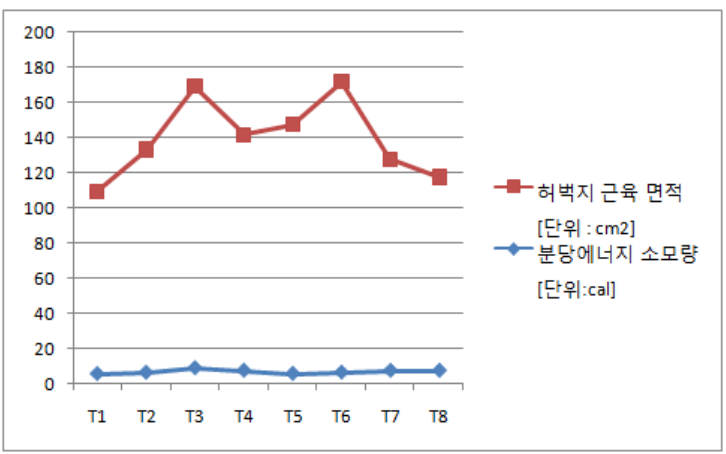

Fig. 8. Thigh muscle area and energy consumption per minute

허벅지 전체면적과 허벅지 근육면적의 상관관계는 Fig. 9에 보이는 것처럼 나타났고, R값은 0.82361 , 표준 편차는 6.29233, P값은 0.00636 으로 나타났다.

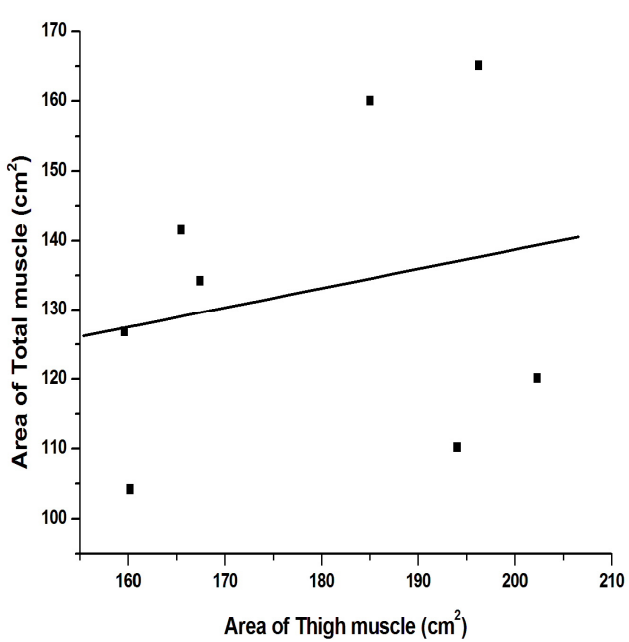

Fig. 9. Thigh circumference and muscle area of the correlation 허벅지 근육면적에 따른 분당 에너지 소모량의 상 관관계는 Fig. 10에 보이는 것처럼 나타났고, R값은 0.67455 , 표준편차는 $0.9206, \mathrm{P}$ 값은 0.04626 으로 나타났 다

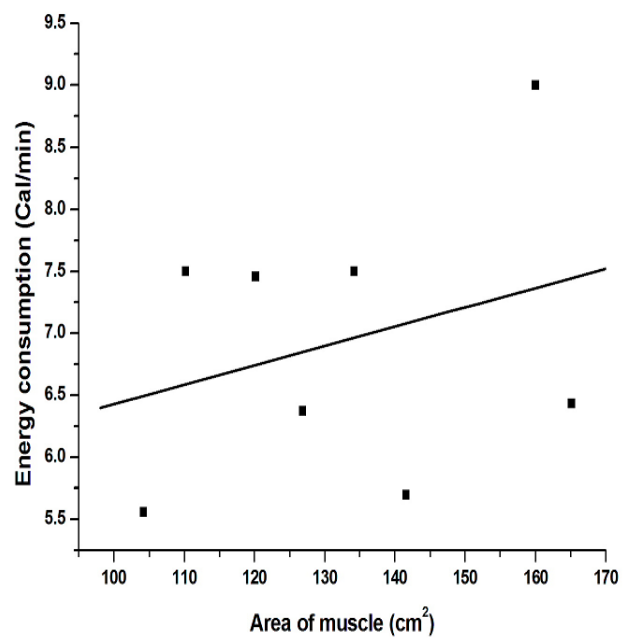

Fig. 10. Thigh muscle area and energy consumption per minute

\section{$\mathrm{V}$. 결론}

본 연구에서는 센서(SenseWear ${ }^{\circledR} \quad \mathrm{PRO}_{2}$ Armband)를 이용하여 태권도의 신체활동량을 획득하였고, Inbody 520 을 통하여 체성분 데이터를 획득 하였으며, CT로 
하체부위(허벅지)를 스캔하여 허벅지 근육면적 데이터 를 추출하였다. 획득된 데이터를 이용하여 허벅지 둘 레와 근육면적의 상관관계, 허벅지 근육면적과 분당 에너지 소모량의 상관관계를 분석하였다.

분석결과 실험자 8 명의 무릎뼈(Pattela) 위 $20 \mathrm{~cm}$ 평 균 허벅지 근육면적은 $132.79 \mathrm{~cm}^{2}$ 였으며, 평균 허벅지 전체 면적은 $178.79 \mathrm{~cm}^{2}$ 이었다. 실험자들의 허벅지 둘 레와 근육면적은 상관관계가 있는 것으로 나타났다.

실험자들의 평균 분당 에너지 소모량은 6.94 였으 며, 허벅지 근육면적과 평균 분당 에너지 소모량도 상 관관계가 있는 것으로 나타났다.

\section{참고문헌}

[1] http;//www.wtf.org.

[2] SangBock Lee, Taesoo Lee, "Analysis on the Amount of Physical Activities of Taekwondo Taegeuk Pumsae Using Accelerometers", Journal of Convergence Information Technology. pp. 48-53, 2010.

[3] Deok-Soo, Chae, "Effects of Taekwondo on Physical Fitness Development in Lower Class's Elementary School", Dept. of Physical Education, Graduate School, Kunsan National University, Kunsan Korea. 2002.

[4] Jaemin Jung, "Analysis of Intensity and Energy expenditure Poom-sae of Taekwondo Practice", Graduate School, Ulsan University, Ulsan Korea pp.1-10, 2005.

[5] SangBock Lee, "Physical Activity Analysis of Taekgeuk Poomsae in Taekwoondo Using Accelerometer", Dept. of Medicine, Graduate School, Chungbuk National University, Cheongju, Korea, pp.16 20, 2008.

[6] GyeHwan Jin, "Context Awareness System Using Acceleration Sensor", Dept. of Biomedical Engineering, Graduate School, Chungbuk National University, Cheongju, Korea, pp.8-14, 2006.

[7] http://www.gehealthcare.com/euen/ct/products/Lightspeed_vct_xte/in dex.html.

[8] http://rsbweb.nih.gov/ij/docs/guide/userguide-Part-I.html. 